\title{
Catalytic Hydrogenation of Dimethyl-Nitrobenzene to Dimethyl-Aniline in a Three-Phase Reactor: Reaction Kinetics and Operation Condition
}

\author{
Mansoor Kazemimoghadam \\ Faculty of Chemical and Chemical Engineering, Malek Ashtar University of Technology, Tehran, Iran
}

\section{Email address:}

mzkazemi@gmail.com

\section{To cite this article:}

Mansoor Kazemimoghadam. Catalytic Hydrogenation of Dimethyl-Nitrobenzene to Dimethyl-Aniline in a Three-Phase Reactor: Reaction Kinetics and Operation Condition. American Journal of Physical Chemistry. Vol. 6, No. 5, 2017, pp. 88-96. doi: 10.11648/j.ajpc.20170605.12

Received: October 2, 2017; Accepted: October 20, 2017; Published: November 27, 2017

\begin{abstract}
The catalytic transfer hydrogenation of dimethyl-nitrobenzene (DN) to Dimethyl-aniline (DA) was studied in the temperature range $343-403^{\circ} \mathrm{K}$, pressure range of $4-10$ bar $\mathrm{H}_{2}$ and ethanol as solvent using $\mathrm{Ni}$ on alumina-silicate as catalyst above agitation speed $800 \mathrm{rpm}$. The substrate feed concentration was varied in the range from 0.124 to $0.745 \mathrm{kmol} / \mathrm{m}^{3}$ while catalyst loading was in the range $4-12 \%(\mathrm{w} / \mathrm{w})$ of dimethyl-nitrobenzene. Dimethyl-aniline was the only reaction product, generated through the hydrogenation of the Nitro group of dimethyl-nitrobenzene. The effects of hydrogen partial pressure, catalyst loading, dimethyl-nitrobenzene concentration and temperature on the reaction conversion have been reported. Near first-order dependence on dimethyl-nitrobenzene concentration and hydrogen pressure were observed for the initial rate of dimethyl-nitrobenzene hydrogenation over the Ni catalyst. Furthermore, an increase in the catalytic activity as the reaction temperature, pressure and weight of catalysts was observed. Conventional Arrhenius behavior was exhibited by catalyst, $\mathrm{Ni}$ showed activation energies of $808 \mathrm{~J} / \mathrm{mol}$.
\end{abstract}

Keywords: Liquid-Phase Hydrogenation, Ni Catalysts, Dimethyl-Nitrobenzene, Dimethyl-Aniline, Operation Condition

\section{Introduction}

Aromatic amines, widely used as important intermediates in the synthesis of chemicals such as dyes, antioxidants, photographic, pharmaceutical and agricultural chemicals, can be obtained easily by the reduction of corresponding aromatic nitro compounds using catalytic hydrogenation and a variety of other reduction conditions. Many reductive agents have been recommended for this transformation and the most classic and practical reductants are zinc, tin, or iron in the presence of an acid. However, most of them lack the chemoselectivity over other functional groups and reduction of aromatic nitro compounds often yield a mixture of products. In addition, the reactions are performed in organic solvents or in the presence of acids, which pose wastehandling problems [1-3].

The selective hydrogenation of nitro compounds is commonly used to manufacture amines, which are important intermediates for dyes, urethanes, agro-chemicals and pharmaceuticals. Hydrogenation of nitro aromatics are used to produce aniline derivatives, which can be carried out in gas or liquid phase by using supported metal catalysts and organic solvents such as alcohols, acetone, benzene, ethyl acetate, or aqueous acidic solutions [4]. The use of these solvents has some drawbacks owing to their toxicity, flammability, or environmental hazards. In addition, the solvent may play a crucial role in the stabilization of reactive intermediates and have a decisive influence on chemical reactions. The rate and the selectivity of aromatic nitrocompounds hydrogenation depend upon different factors such as temperature, hydrogen pressure and concentrations of catalyst and a hydrated compound [5-7]. The main purpose of this study was to evaluate the effects of parameters such as hydrogen pressure and temperature on the rate of dimethylnitrobenzene hydrogenation over a Ni catalyst in ethanolwater two components solvent. Solvents are known to have a 
significant effect on the rate of catalytic hydrogenations. The effects of solvent are attributed to various factors, which include solubility of hydrogen, thermodynamic interaction of solvent with the reactants and products, agglomeration of catalysts in some solvent and competitive adsorption of solvent [8-10]. The solvent employed was ethanol. Further, the recovery of ethanol in the presence of water (formed during the reaction) will be easy. Hence, ethanol was used as a solvent in this study [11].

In this paper the influence of Operation conditions and loading of catalyst on the catalytic activity for dimethylnitrobenzene hydrogenation in an alcoholic solution is presented. The effect of operating conditions on the reactor performance was studied by comparing the conversion of dimethyl-nitrobenzene, under different reaction conditions.

\section{Experimental}

The details of the experimental set-up, experimental procedures and analytical techniques are presented in this section.

\subsection{Materials}

All the chemicals used were purchased from Pure Chemicals and used without further purification. Dimethylnitrobenzene was used. A 40 wt.\% Ni catalyst on aluminasilicate support used to reduction of dimethyl-nitrobenzene. The average size of $\mathrm{Ni}$ particles obtained was shown to be $50 \mu \mathrm{m}$. dimethyl-nitrobenzene, ethanol, and distillated water used were of laboratory reagent grade. Hydrogen (cylinder purity $99.98 \%$ ) was used.

\subsection{Experimental Set-up}

The hydrogenation process was carried out in an isothermal 6L stainless steel autoclave, which allows isothermal conditions due to a heating jacket (Figure 1). The reactor having a diameter of $200 \mathrm{~mm}$ (impeller diameter 80 $\mathrm{mm}$ ) was equipped with an electrically heated jacket, a turbine agitator and a variable-speed magnetic drive ensuring zero leaks. The temperature and the speed of agitation were controlled by means of a controller. The gas inlet, gas release valve, cooling water feed line; pressure gauge and rupture disk were situated on top of the reaction vessel. The liquid sample line and the thermocouple well were immersed in the reaction mixture. The reactor was also provided with a cooling coil. In order to ensure good bubble dispersion, the gas injection is performed through a plunging tube whose exit opening is placed right below the agitation mobile. The hydrogen was supplied at the same rate that it was consumed under isobaric reaction conditions. The samples for the analyses were drawn via a sampling tube. The experiments were carried out using the following procedure; first, DN $(99 \%)$ was dissolved in a mixture of $91 \%$ wt of Ethanol $(99.9 \%)$ and $9 \%$ wt distilled water. The reactor was filled with $3500 \mathrm{ml}$ solution and the solid catalyst (from 30 to $70 \mathrm{~g}$ ) was added. Second, the reaction was initiated by removing the air from the reactor by purging with hydrogen and stirring the solution at $800 \mathrm{rpm}$. The temperature was controlled at $373^{\circ} \mathrm{K}$ and the hydrogen partial pressure was kept constant between 4 and 10 bars. The samples were analyzed by gas chromatography and a FID detector [12-14].

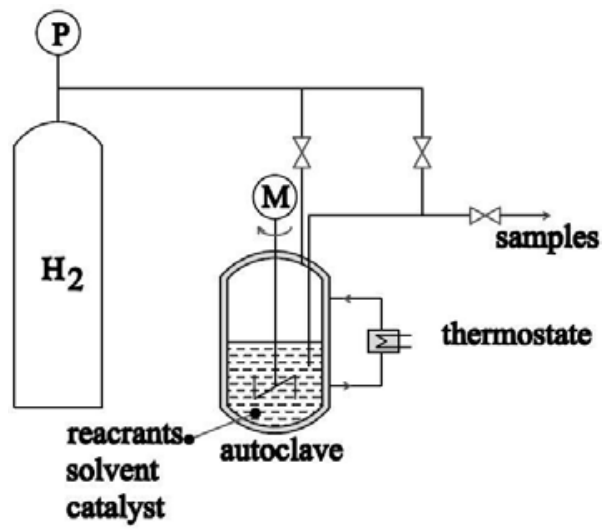

Figure 1. Experimental set-up for the liquid hydrogenation of dimethylnitrobenzene.

\section{Experimental Procedure}

The reactor was first charged with appropriate quantities of the dimethyl-nitrobenzene, the solvent and the catalyst. It was then purged with nitrogen, prior to the start of the experiment to ensure an inert atmosphere in the reactor. Hydrogen from the cylinder was introduced into the reactor and nitrogen was replaced with it. All the lines were closed. The reactor contents were heated to the desired temperature. The autoclave was then pressurized with hydrogen to get the desired partial pressure of hydrogen. Agitation was then started at the predetermined speed. The consumption of hydrogen due to reaction as well as due to small sampling led to decrease in the total pressure as indicated on the pressure gauge. So, more hydrogen was charged intermittently from the cylinder through manually operated control valve, thus maintaining a constant partial pressure of hydrogen. Samples were withdrawn periodically after sufficient flushing of the sample line with the reaction mixture [15-17].

\section{Results and Discussion}

Heterogeneous catalytic hydrogenation is a reaction involving gas-liquid-solid-phase operation. Various steps occur in series when a gas-liquid-solid reaction occurs [18]. The minimum speed of agitation used was higher than the minimum speed required for the suspension of the catalyst particles. The following assumption was made while studying the heterogeneous catalytic hydrogenation reactions:

1. The activity of the catalyst is maintained throughout in all the experiment, that is, that no poisoning or deactivation of the catalyst occurs.

2. Desorption of the products offered no resistance [19].

The main objective of the work was to investigate the effect of following various process parameters on conversion 
of nitroaromatic to aromatic amine.

\subsection{Effect of the Dimethyl-Nitrobenzene Concentration}

The effect of dimethyl-nitrobenzene concentration on the hydrogenation rate was examined by using different dimethyl-nitrobenzene concentrations $(0.12,0.25,0.37,0.50$, 0.62 and $0.75 \mathrm{~mol} / \mathrm{lit}$ ) in ethanol. Figure 2 shows, for the $\mathrm{Ni}$ catalyst, the evolution of the conversion level with time at constant hydrogen pressure (10 bars), temperature $\left(363^{\circ} \mathrm{K}\right)$ and weight of catalyst $(50 \mathrm{~g})$. Percent conversion was measured using dimethyl-nitrobenzene in the range 1-3 mol in $3500 \mathrm{~cm}^{3}$ ethanol. After reaction time of $210 \mathrm{~min}$, it was observed that with an increase in substrate concentration (dimethyl-nitrobenzene) percent conversion increased almost linearly up to $2.7 \mathrm{~mol}$ of dimethyl-aniline then surprisingly started decreasing. An increase in the activity as decreasing the dimethyl-nitrobenzene concentration can be observed. However, if the conversion of the reaction (expressed as the percentage of dimethyl-nitrobenzene hydrogenated in the mixture) is studied as a function of the reaction time, significant changes are observed. At short reaction times, dimethyl-aniline was produced, but at longer reaction times rate of conversion is lower up to reaching a constant value. The higher proportion of dimethyl-nitrobenzene found at lower conversion levels is attributed to the fact that the lower dimethyl-nitrobenzene concentration ratio to catalyst loading is easier to hydrogenate compared to the higher dimethylnitrobenzene concentration.

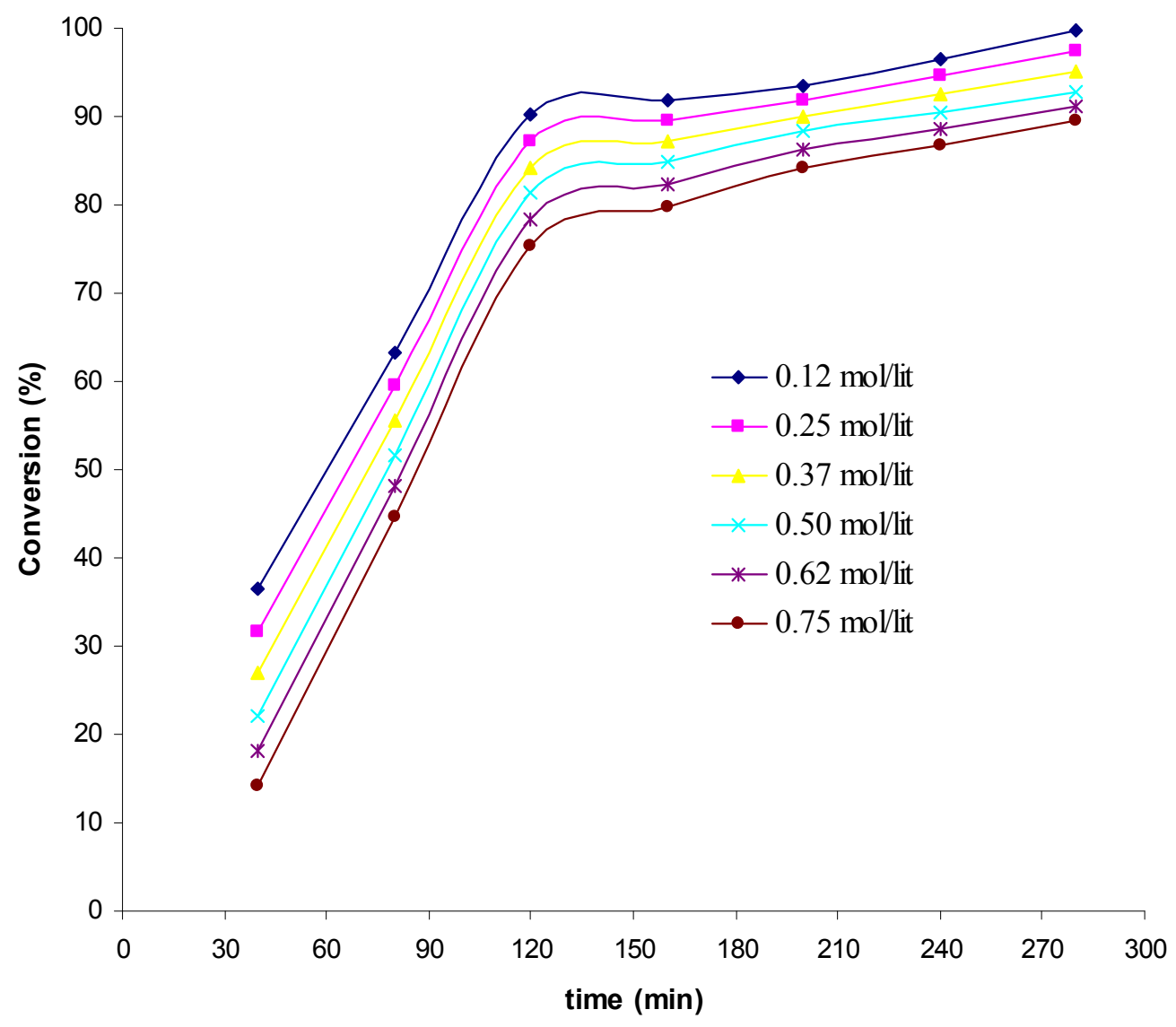

Figure 2. Evolution of the conversion level with time at different dimethyl-nitrobenzene concentration.

Figure 2 shows that decrease in dimethyl-nitrobenzene concentration increases the conversion. The conversion is lower at higher dimethyl-nitrobenzene concentration indicating that the rate of dimethyl-aniline formation has a dependency on the dimethyl-nitrobenzene concentration. Dimethyl-nitrobenzene concentration was varied from 1.0 to $0.05 \mathrm{~mol}$ for the catalytic hydrogenation of dimethylnitrobenzene. We observed that the rate of dimethyl-aniline formation at high concentrations of dimethyl-nitrobenzene is low because of substrate inhibition effect present at such high concentrations. Another reason could be that at such high concentrations, external mass transfer resistance may become significant because of the low solubility of hydrogen at high concentrations of the reactant. Therefore low concentrations $(0.25-0.5 \mathrm{~mol} / \mathrm{l})$ of dimethyl-nitrobenzene were used for the kinetics studies.

The effect of time on concentration of dimethylnitrobenzene and dimethyl-aniline is shown in Figure 3. The dimethyl-aniline concentration increases with decrease in dimethyl-nitrobenzene concentration with time. The rate was also reported as proportional to the concentration of dimethyl-nitrobenzene for its reduction with hydrogen. 


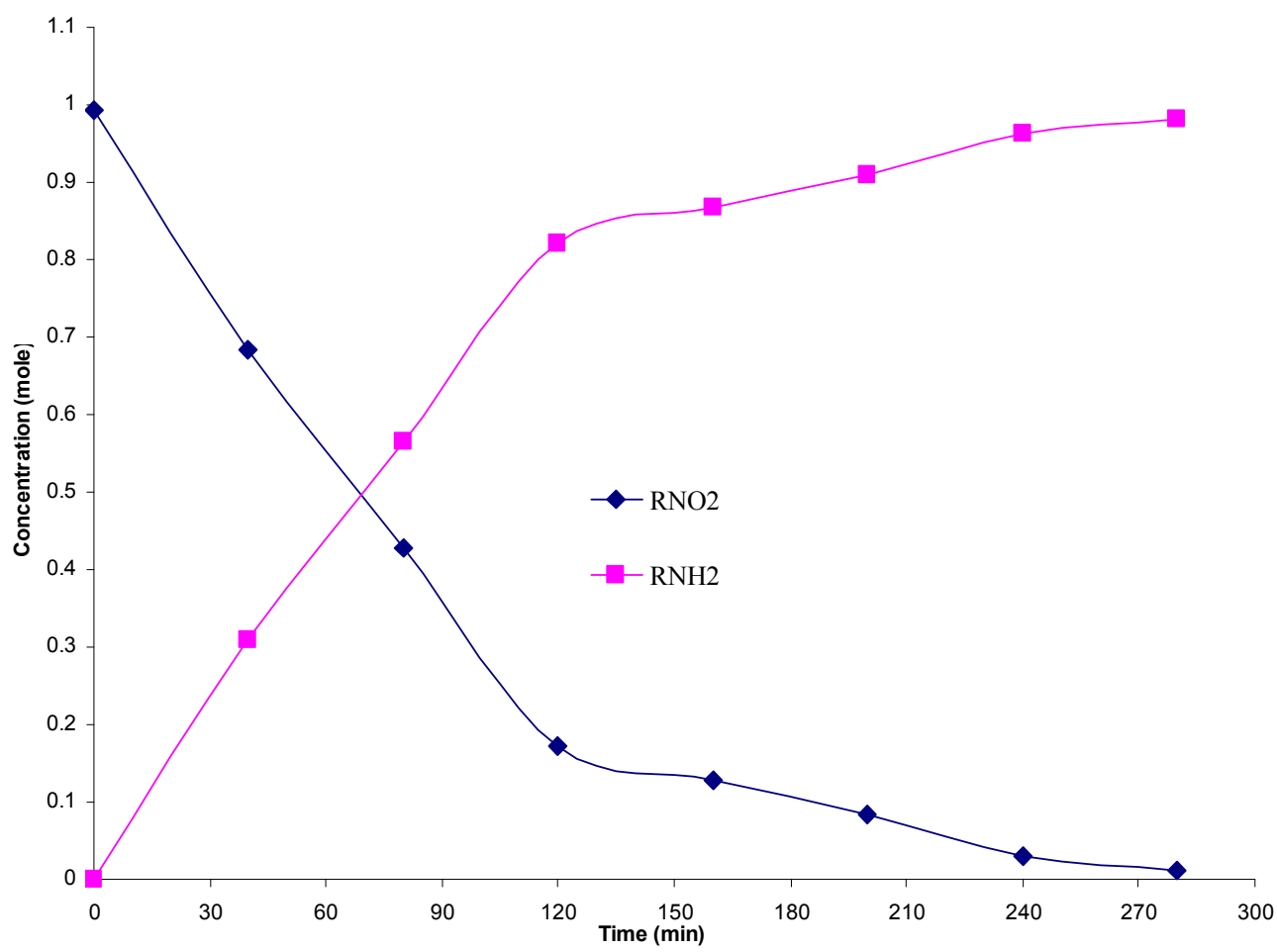

Figure 3. Dimethyl-nitrobenzene and dimethyl-aniline concentrations in solution verses time of reaction.

In order to evaluate the reaction order with respect to dimethyl-nitrobenzene, the initial reaction rate (ro) was obtained and a plot of $\log$ ro versus $\log [\mathrm{DN}]$, where $\mathrm{DN}$ is the initial dimethyl-nitrobenzene concentration allowed one to obtain the reaction order from the slope. The results showed that under the reaction conditions studied the system exhibited a reaction order of $-1.0 \pm 0.1$ for Ni catalyst. Figure 4 shows the effect of reactant concentration on the initial rate of catalytic hydrogenation. The initial rate was found to increase linearly with the dimethyl-nitrobenzene concentration indicating first order dependence on the reactant concentration.

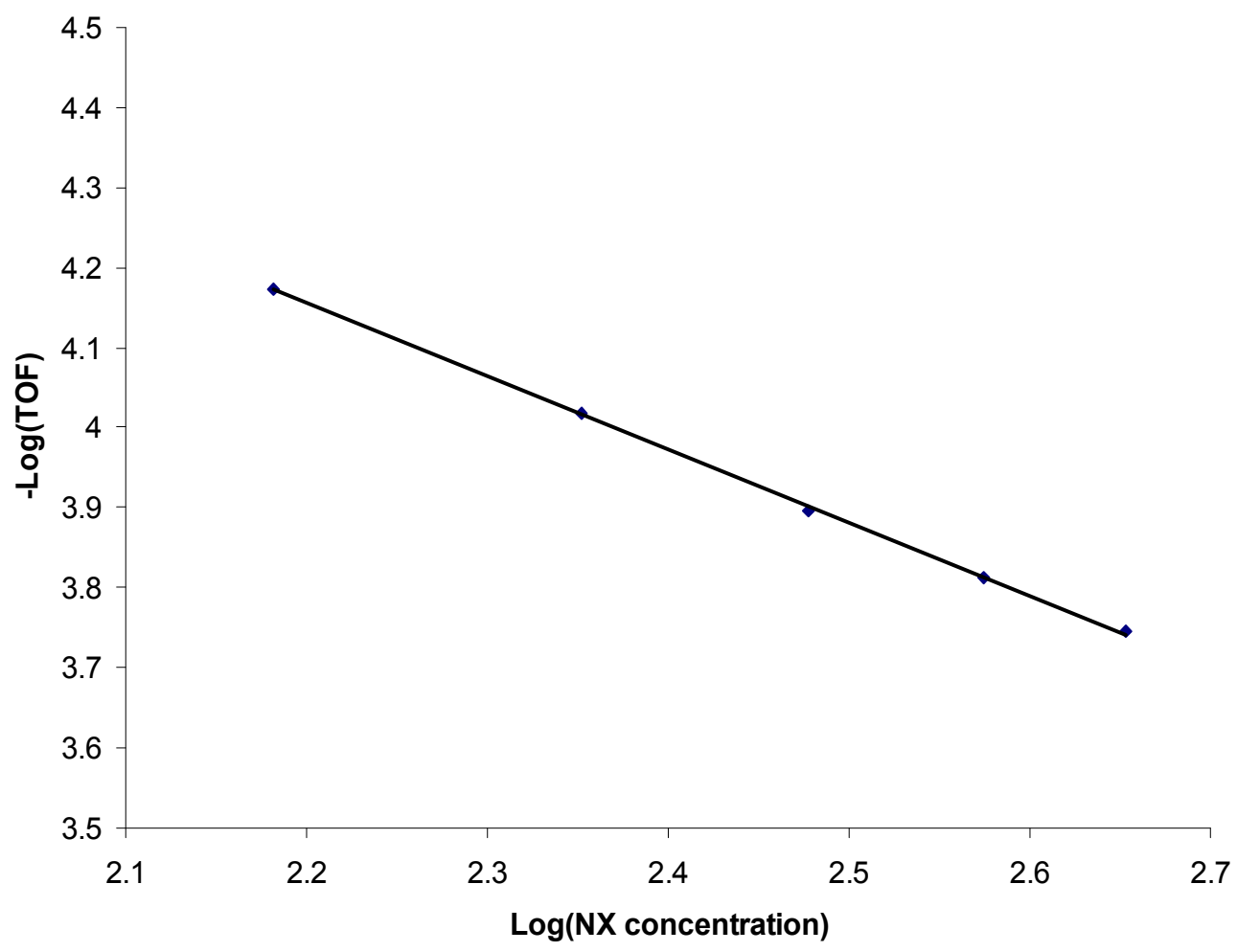

Figure 4. $\log \left(\right.$ TOF) vs. log dimethyl-nitrobenzene concentration ( $\mathrm{H}_{2}$ pressure $700 \mathrm{kPa}$, catalyst loading $\left.12.5 \mathrm{kgm}^{-3}, 363^{\circ} \mathrm{K}\right)$. 


\subsection{Effect of Hydrogen Partial Pressure}

To study the effect of pressure on conversion of dimethylnitrobenzene, experiments were carried out in the pressure range of 4-10 bars at a dimethyl-nitrobenzene concentration of $0.25 \mathrm{~mol} / \mathrm{L}$ in ethanol, temperature of $363^{\circ} \mathrm{K}$. The catalyst loading was kept constant by varying the residence time. Figure 5 shows a plot of the conversion vs. residence time at hydrogen pressures $4,5.5,7,8.5$ and 10 bars.

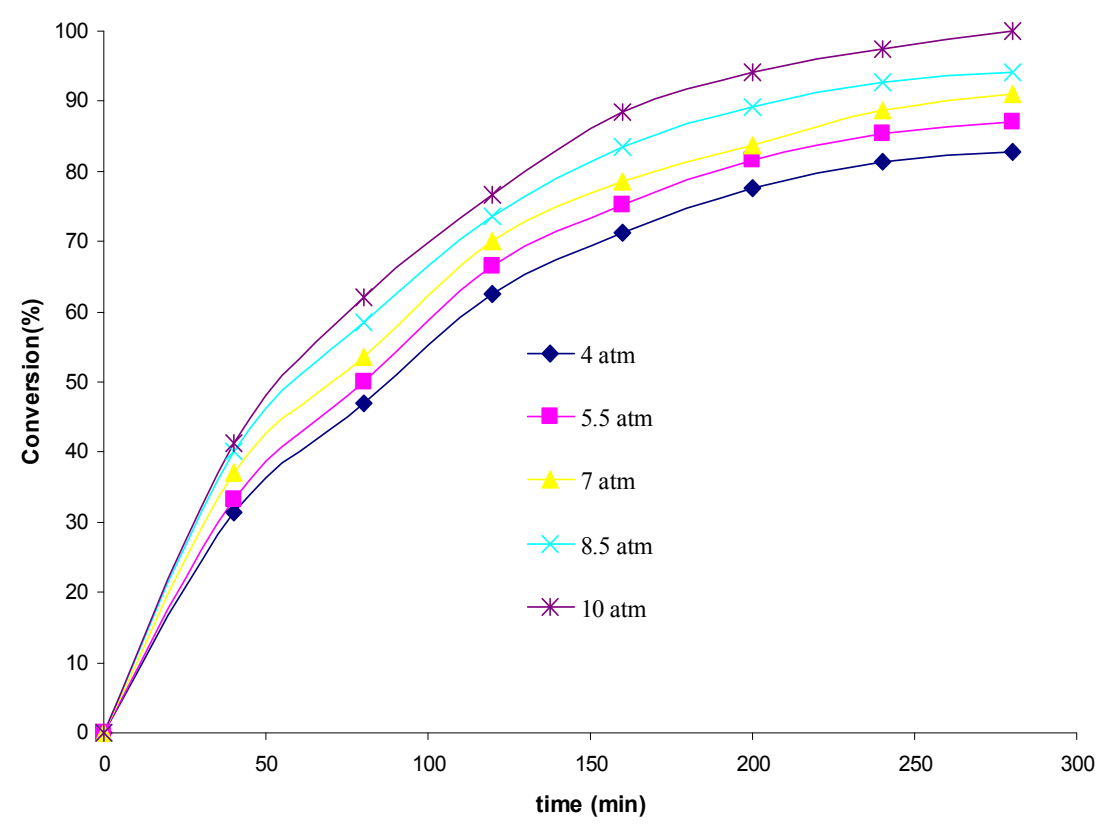

Figure 5. Evolution of the conversion level with time at different pressure.

Figure 5 indicates that the conversion increases with increase in pressure in the range of pressures studied. This increase in conversion of dimethyl-nitrobenzene is attributed to the increase in the concentration of dissolved hydrogen with increase in pressure, thereby resulting in a higher reaction rate. However, pressure has effect on the conversion at constant loading catalyst because the increase in the reaction rate at higher pressure is countered by the decrease in the catalyst loading. It can be seen that the activity increases as hydrogen pressure increases. When hydrogen pressure increases to $4 \mathrm{~atm}$ the rate of dimethyl-nitrobenzene hydrogenation rate increases linearly, then this linearity is destroyed and when the pressure reaches 10 atm the rate of dimethyl-nitrobenzene hydrogenation ceases to be dependent upon hydrogen pressure.

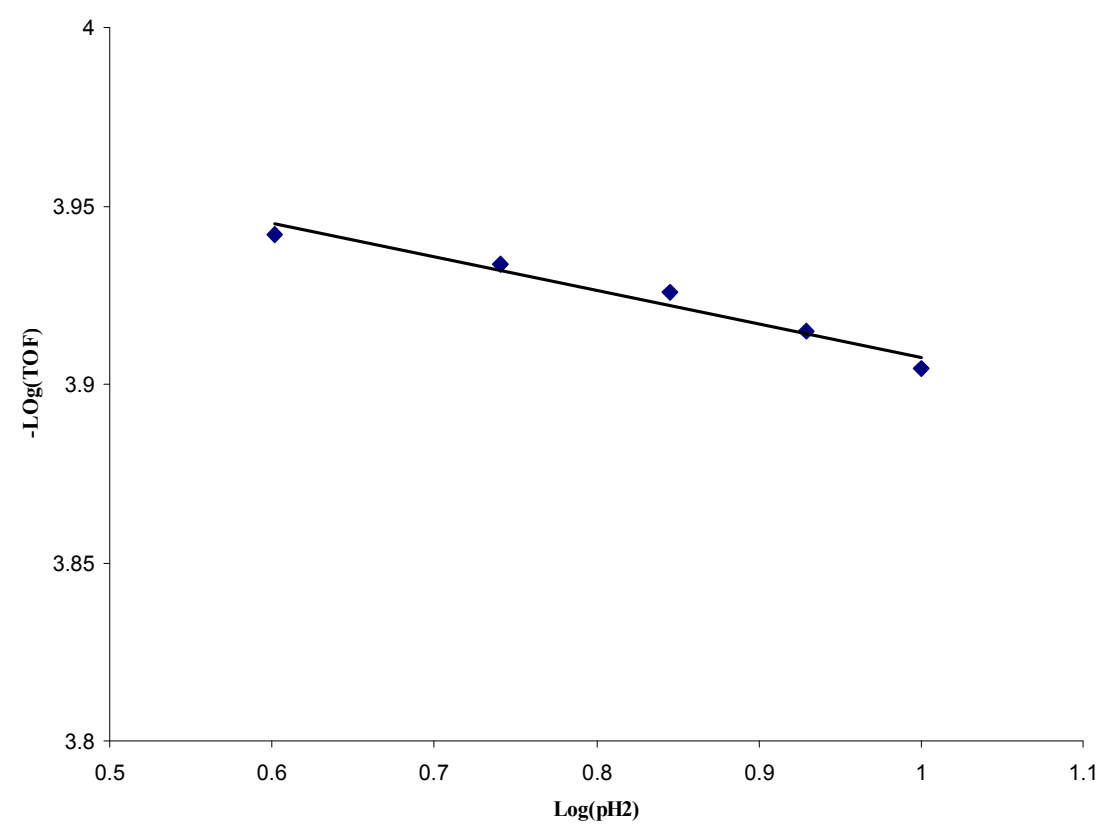

Figure 6. Log (TOF) vs. Log hydrogen pressure (initial DN concentration $0.5 \mathrm{kmolm}^{-3}$, Catalyst loading $12.5 \mathrm{kgm}^{-3}, 363^{\circ} \mathrm{K}$ ). 
The effect of hydrogen partial pressure on the initial rate was studied in the range of $400-1000 \mathrm{kPa}$ (Figure 6). The initial rate was found to increase linearly with the hydrogen partial pressure. After obtaining the initial reaction rate, an appropriate plot, log ro versus log hydrogen pressure (Figure 6); allow us to obtain the reaction order with respect to hydrogen. This procedure leads to order $1.0 \pm 0.1$ for $\mathrm{Ni}$ catalyst. These results are shown that reaction order, being a first-order dependence on hydrogen pressure for the $\mathrm{Ni}$ catalyst. On the other hand, a first-order dependence on hydrogen for Ni catalyst was found.

\subsection{Effect of Temperature}

Catalytic transfer hydrogenation is highly temperature dependant. The reaction did not proceed at room temperature and at lower temperature partially hydrogenated product was obtained, thus the effect of temperature was studied from 343 ${ }^{\circ} \mathrm{K}$ to $403^{\circ} \mathrm{K}$ under otherwise similar conditions (Figure 7 ).

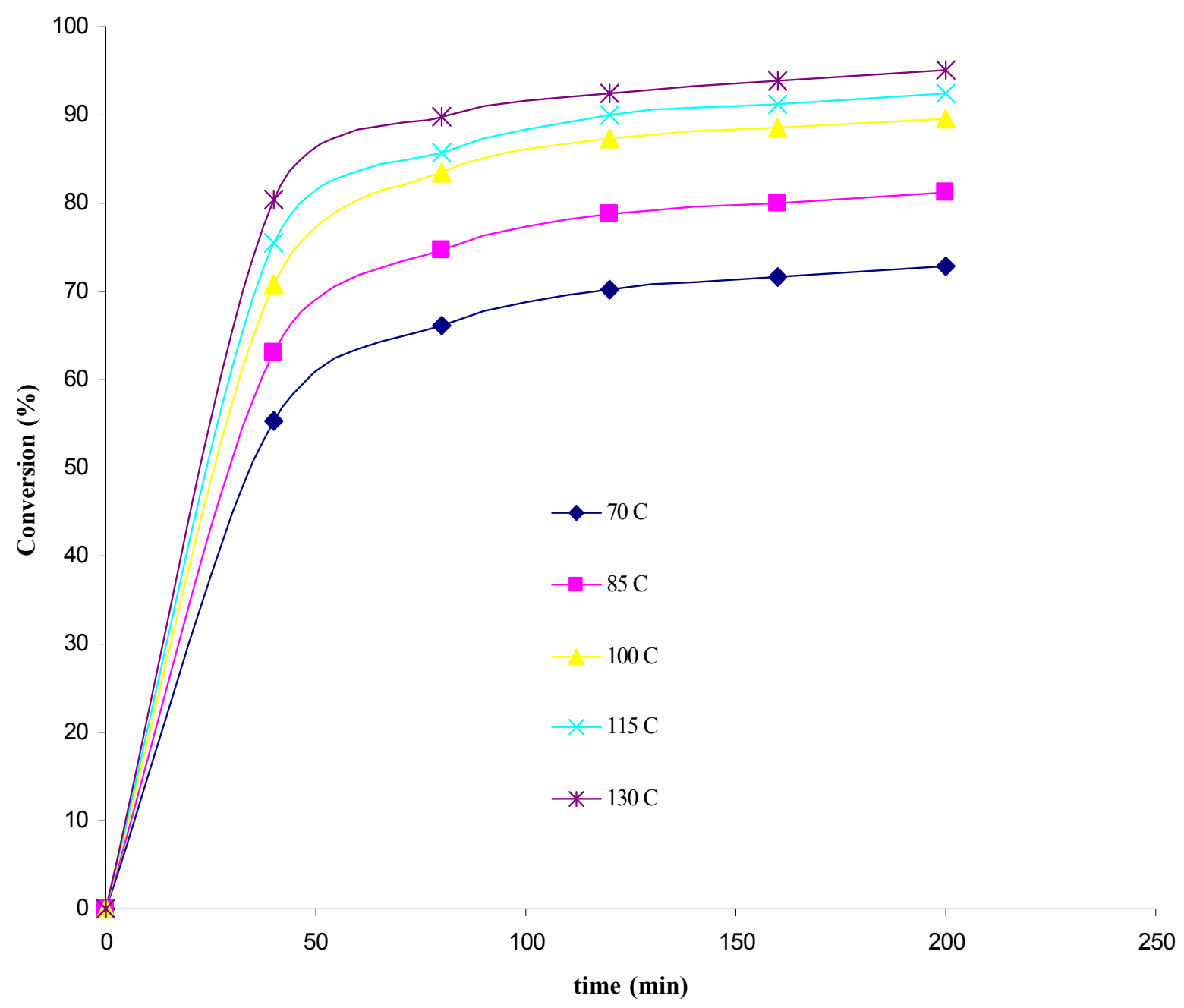

Figure 7. Evolution of the conversion level with time at different temperature.

The conversion of dimethyl-nitrobenzene increased with increase in the temperature of the reaction. The Figure 7 shows the evolution of the conversion with time at different reaction temperatures for a $\mathrm{Ni}$ catalyst. An important enhancement in the catalytic activity as reaction temperature increases can be noted. However, no changes in the selectivity were detected and only dimethyl-aniline was the product obtained. To study the effect of temperature on conversion of dimethyl-nitrobenzene, experiments were carried out in the temperature range of $343-403{ }^{\circ} \mathrm{K}$ at a substrate concentration of $2 \mathrm{~mol} / \mathrm{L}$ in ethanol, pressure of 103 psig and a catalyst loading (1\% cat/organic phase) with 3500 $\mathrm{cm}^{3}$ solution. Figure 7 show that with increase in temperature, the conversion increase at all the temperature levels. These results were obtained after $150 \mathrm{~min}$ of reaction time. At temperature of $403{ }^{\circ} \mathrm{K}$ more than $95 \%$ conversion was obtained at defined conditions.

\subsection{Effect of Catalyst Concentration}

The effect of catalyst (Ni) concentration on conversion of dimethyl-nitrobenzene was studied in the concentration range of 0.00403-0.00939 mol/lit of organic phase, while keeping the other experimental conditions constant as shown in Figure 8 . 


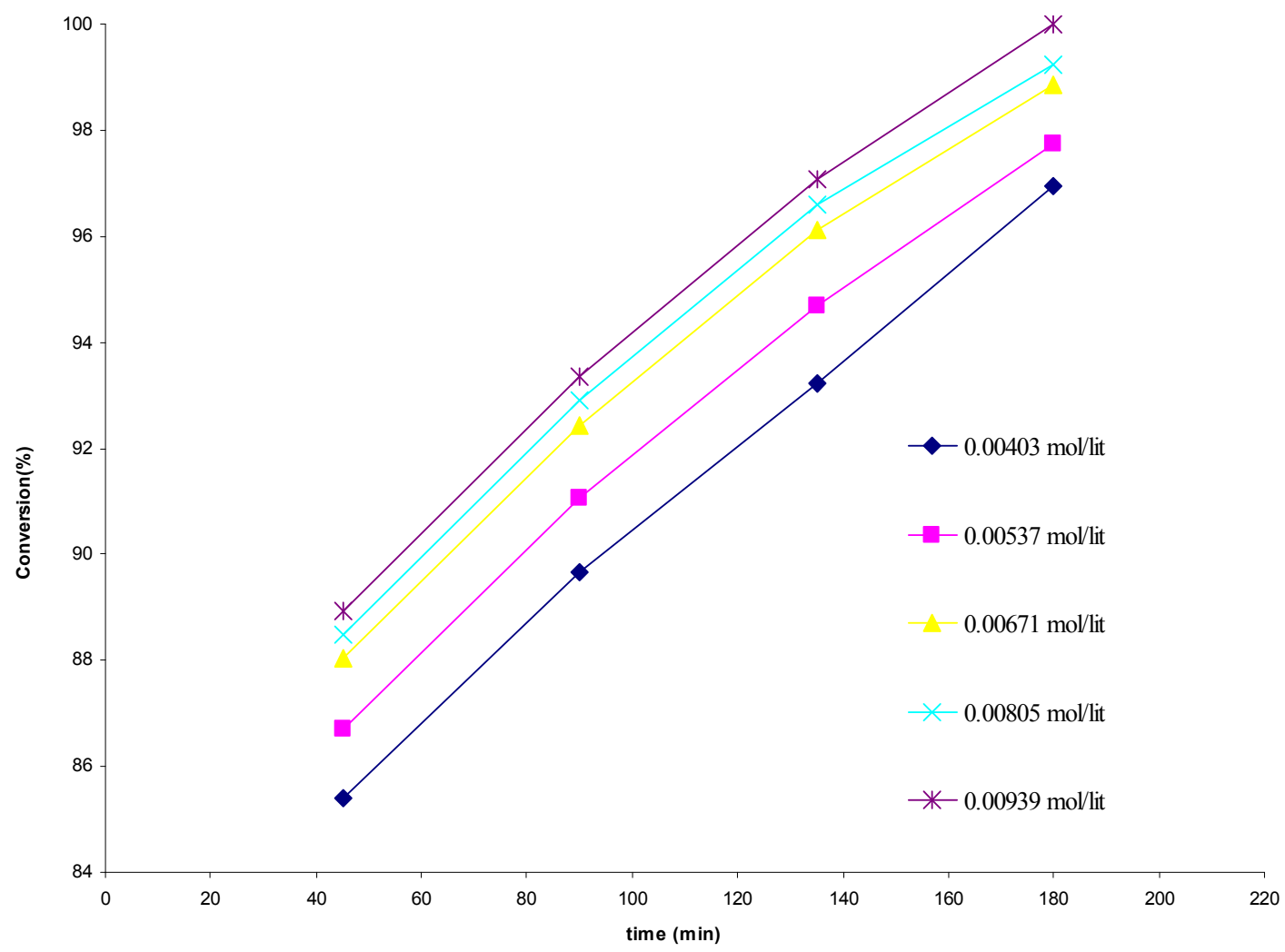

Figure 8. Evolution of the conversion level with time at different weight of catalyst.

The conversion increased with increase in [catalyst], which is due to the proportional increase in the number of active sites. From the results obtained we can say that as the concentration of catalyst increases, the conversion of dimethyl-nitrobenzene to dimethyl-aniline with $100 \%$ selectivity. An increase in the activity as the catalyst weight increases can be noted. As expected, it shows a linear dependency in the initial reaction rate with the catalyst weight, as it can be seen in Figure 9. Rate of reaction is directly proportional to [catalyst] base on the entire liquid phase volume.

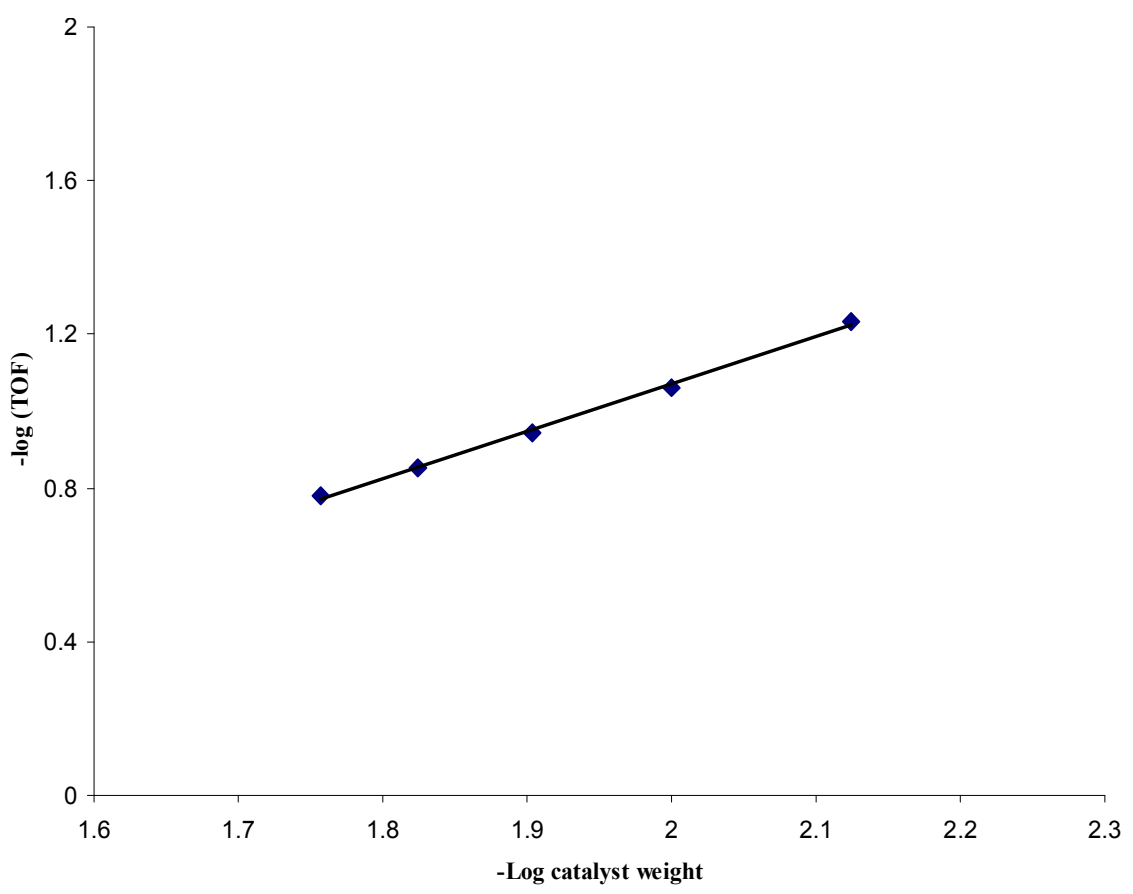

Figure 9. $\log (\mathrm{TOF})$ vs. log catalyst weight $\left(363^{\circ} \mathrm{K}, \mathrm{H}_{2}\right.$ pressure $\left.1000 \mathrm{kPa}\right)$. 


\section{Reaction Kinetic Data}

The rate of reaction was evaluated by fitting the DN concentration vs. time plot to a polynomial followed by differentiation and calculation at various time intervals. The classical approach of reporting kinetic data in terms of turnover frequency (TOF) defined as

$$
T O F=\frac{\text { no. of molecules reacted }}{\text { (active centers) (time) }}
$$

Would have been the ideal choice. However, gaining knowledge of the active centers on the catalyst surface is a rather difficult task necessitating highly sophisticated techniques. Chemisorption of $\mathrm{H}_{2}$ (or DN) would have given some idea. Our catalyst particles are not spherical in shape but of irregular shape. It was, therefore, decided to express rates as mol kgcat ${ }^{-1} \mathrm{~min}^{-1}$. After all, the active centers are proportional to the catalyst weight. From a process engineering point of view, in the absence of exact knowledge of active centers, this simpler approach would be more comprehensive. The effect of catalyst loading on the initial rates was studied in the range of catalyst concentrations
$8.57-20 \mathrm{kgm}^{-3}$, at $363{ }^{\circ} \mathrm{K}$ and $1 \mathrm{MPa}$ hydrogen partial pressure. These results are shown in Figure 4. The initial rates increased linearly with the catalyst loading in the range studied. The effects of various reaction parameters such as hydrogen partial pressure and feed DN concentration on the initial rate were studied at $343-403{ }^{\circ} \mathrm{K}$ and are described below.

\subsection{Effect of Hydrogen Partial Pressure}

The effect of hydrogen partial pressure on initial rates was studied in the range of hydrogen partial pressures $0.4-1 \mathrm{MPa}$ at an initial DN concentration of $0.5 \mathrm{kmolm}^{-3}$. The results are shown in Figure 5. These results indicated that the order with respect to hydrogen was far less than unity.

\subsection{Effect of Initial Dimethyl Nitrobenzene Concentration}

Experiments were conducted at varying feed DN concentrations in the range $0.25-0.75 \mathrm{kmolm}^{-3}$, at $1 \mathrm{MPa}$ hydrogen partial pressure. The dependence of the initial rates on feed DN concentration is presented in Figure 6.

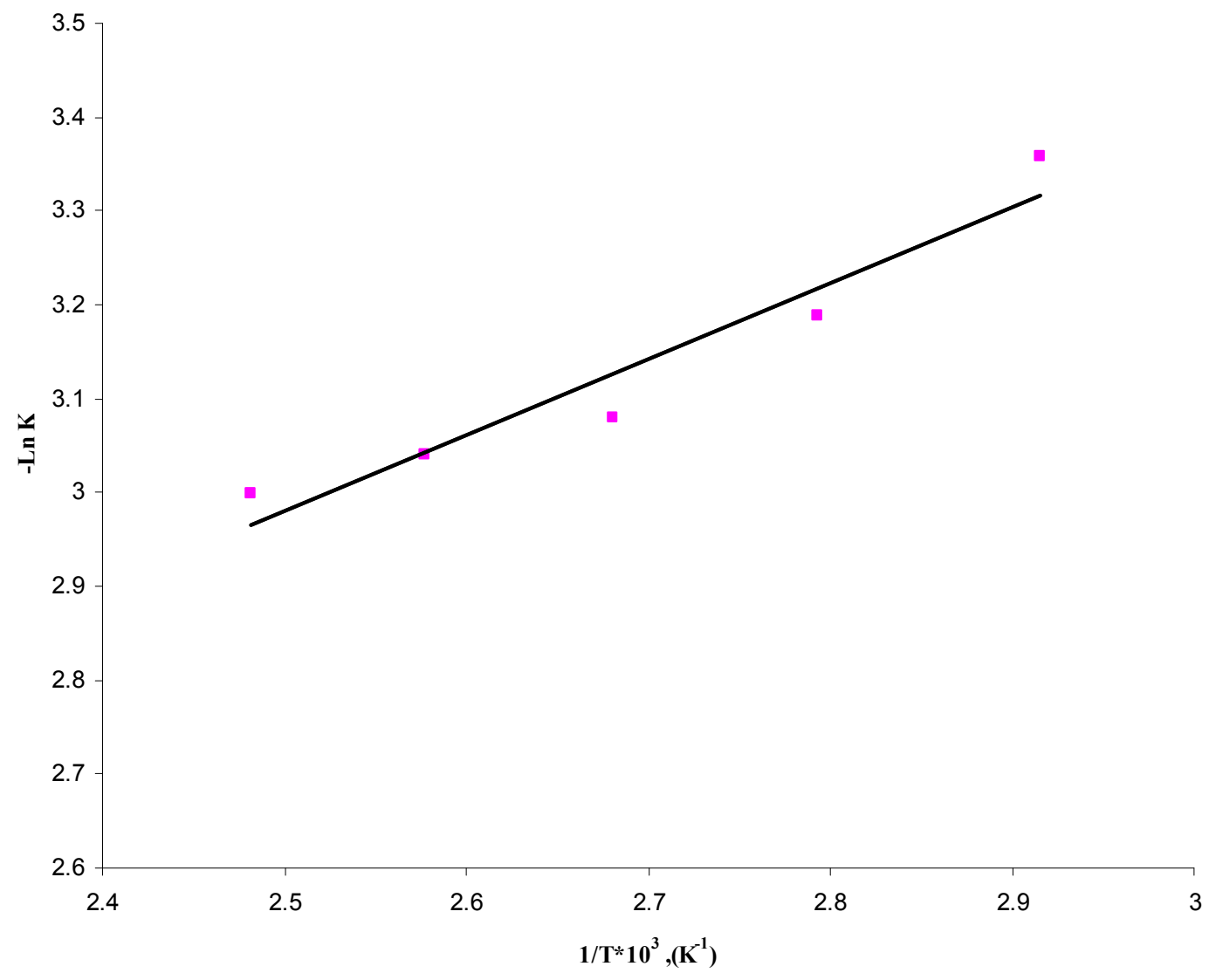

Figure 10. Arrhenius plot for $40 \%$ Ni catalyst.

\subsection{Analysis of Initial Rate Data}

The effects of hydrogen partial pressure and catalyst loading on the initial rate of reactions are shown in Figures 6 and 9 . The rate was found to increase linearly with the catalyst loading and with the hydrogen partial pressure for the reaction. The results indicate first order dependence of the initial rate of reaction on the hydrogen partial pressure for the reaction. Figure 4 shows that the initial rate of dimethylnitrobenzene hydrogenation increases linearly with 
increasing the dimethyl-nitrobenzene concentration indicating the first order dependence of initial rate on dimethyl-nitrobenzene concentration. This order was confirmed by applying initial rate at different temperatures. These are found to be first order with respect to hydrogen for the reaction, first order with respect to dimethyl-nitrobenzene concentration for dimethyl-aniline formation. It was found that reaction temperature had a strong effect on the initial rate of the reactions. The initial rates were found to increase with increasing the reaction temperature for the reaction. The effect of temperature on the rate of reaction of dimethylnitrobenzene with aqueous ethanol was studied in the range of $343-403^{\circ} \mathrm{K}$ in the presence of a catalyst, Ni. The reaction rate increases with temperature for the dimethylnitrobenzene. The initial rates were calculated at different temperatures and an Arrhenius plot of $\ln$ (initial rate) against 1/T $\left(K^{-1}\right)$ was made (Figure 10). The apparent activation energies for this kinetically controlled reaction were calculated from the slopes of the straight lines as $808 \mathrm{~J} / \mathrm{mol}$. The high values of apparent activation energy confirm that the reaction systems are kinetically controlled.

\section{Conclusions}

The kinetics of liquid-phase catalytic hydrogenation of dimethyl-nitrobenzene to dimethyl-aniline was studied in a stirred three-phase slurry reactor between 343 and $403^{\circ} \mathrm{K}$ using a hydrogen partial pressure range of 4-10 bars, with a $\mathrm{Ni}$ catalyst. Ethanol was used as the reaction medium. The effects of various parameters on the reactions of DN were studied to determine the dependencies of the reaction rates on the concentrations of various species present in the reaction system. The following sections report the effects of different parameters on the rates of dimethyl-nitrobenzene reduction by aqueous ethanol in the presence of a catalyst, $\mathrm{Ni}$.

\section{References}

[1] J. Maria, C. Barrera, Naphthalene hydrogenation over Mgdoped $\mathrm{Pt} / \mathrm{Al}_{2} \mathrm{O}_{3}$, Catalysis Today, 296 (2017) 197-204.

[2] P. Haldar, V. V. Mahajani, Catalytic transfer hydrogenation: o-nitro anisole to o-anisidine, some process development aspects, Chemical Engineering Journal 104 (2004) 27-33.

[3] Y. Liu, X. Deng, CO hydrogenation to higher alcohols over $\mathrm{Cu} \mathrm{Zn} \mathrm{Al}$ catalysts without promoters: Effect of $\mathrm{pH}$ value in catalyst preparation, Fuel Processing Technology, 167(2017) 575-581.

[4] I. Maizatul, S. Shaharun, Carbon nanofiber-based copper/zirconia catalyst for hydrogenation of $\mathrm{CO}_{2}$ to methanol, Journal of $\mathrm{CO}_{2}$ Utilization, 21 (2017) 145-155.

[5] Nivedita S. Chaubal, Manohar R. Sawant, Nitro compounds reduction via hydride transfer using mesoporous mixed oxide catalyst, Journal of Molecular Catalysis A: Chemical 261 (2006) 232-241.
[6] S. Lee, Z. $\mathrm{Yu}$, Acetophenone hydrogenation on $\mathrm{Rh} / \mathrm{Al}_{2} \mathrm{O}_{3}$ catalyst: Intrinsic reaction kinetics and effects of internal diffusion, Chemical Engineering Journal, 288 (2016) 711-723.

[7] A. jeli, M. Grilc, Catalytic hydrogenation and hydrodeoxygenation of lignin-derived model compound eugenol over $\mathrm{Ru} / \mathrm{C}$ : Intrinsic microkinetics and transport phenomena, Chemical Engineering Journal, 333 (2018) 240 259.

[8] Sunil K. Maity, Narayan C. Pradhan, Anand V. Patwardhan, Kinetics of the reduction of nitrotoluenes by aqueous ammonium sulfide under liquid-liquid phase transfer catalysis, Applied Catalysis A: General 301 (2006) 251-258.

[9] D. Perz, C. Fuentes, Study of the selective hydrogenation of 1, 3-butadiene in three types of industrial reactors, Fuel, 149 (2015) 34-45.

[10] T. Swathi, G. Buvaneswari, Application of $\mathrm{NiCo}_{2} \mathrm{O}_{4}$ as a catalyst in the conversion of p-nitrophenol to p-aminophenol, Materials Letters 62 (2008) 3900-3902.

[11] M. Walesa, L. Joos, Composite catalytic tubular membranes for selective hydrogenation in three-phase systems, Catalysis Today, 268 (2016) 12-18.

[12] Sachin U. Sonavane, Manoj B. Gawande, Sameer S. Deshpande, A. Venkataraman, Radha V. Jayaram, Chemo selective transfer hydrogenation reactions over nanosized c$\mathrm{Fe}_{2} \mathrm{O}_{3}$ catalyst prepared by novel combustion route, Catalysis Communications 8 (2007) 1803-1806.

[13] Jia-Huei Shen, Yu-Wen Chen, Catalytic properties of bimetallic NiCoB nanoalloy catalysts for hydrogenation of $\mathrm{p}$ chloronitrobenzene, Journal of Molecular Catalysis A: Chemical 273 (2007) 265-276.

[14] M. Li, D. Wang, Surfactant-assisted hydrothermally synthesized $\mathrm{MoS}_{2}$ samples with controllable morphologies and structures for anthracene hydrogenation, Chinese Journal of Catalysis, (2017) 597-606.

[15] Ekaterina K. Novakova, Leanne McLaughlin, Robbie Burch, Paul Crawford, Ken Griffin, Christopher Hardacre, Peijun Hu, David W. Rooney, Palladium-catalyzed liquid-phase hydrogenation/hydrogenolysis of disulfides, Journal of Catalysis 249 (2007) 93-101.

[16] Yu-Zhi Haoa, Zuo-Xi Li, Jin-Lei Tian, Synthesis, characteristics and catalytic activity of water-soluble $[\mathrm{Pd}$ (lysine $\cdot \mathrm{HCl})(\mathrm{Cl})_{2}$ ] complex as hydrogenation catalyst, Journal of Molecular catalysis A: Chemical 265 (2007) 258-267.

[17] R. Soeiro, S. Richard, Influence of noble metals (Pd, Pt) on the performance of $\mathrm{Ru} / \mathrm{Al}_{2} \mathrm{O}_{3}$ based catalysts for toluene hydrogenation in liquid phase, Applied Catalysis A: General, 525 (2016) 41-49.

[18] Qiong Xua, Xin-Mei Liu, Jun-Ru Chen, Rui-Xiang Li, XianJun Li, Modification mechanism of $\mathrm{Sn}^{4+}$ for hydrogenation of p-chloronitrobenzene over PVP-Pd/ $\mathrm{Al}_{2} \mathrm{O}_{3}$, Journal of Molecular Catalysis A: Chemical 260 (2006) 299-305.

[19] F. Lali, G. Bottcher, Preparation and characterization of $\mathrm{Pd} / \mathrm{Al}_{2} \mathrm{O}_{3}$ catalysts on aluminum foam supports for multiphase hydrogenation reactions in rotating foam reactors, Chemical Engineering Research and Design, 94 (2015) 365-374. 